\title{
EAFI: Examination of Anomalous Fantasy and Imagination
}

\author{
Andreas Rosén Rasmussen ${ }^{\mathrm{a}}$ Helene Stephensen ${ }^{\mathrm{a}}$ Josef Parnas ${ }^{\mathrm{a}, \mathrm{b}}$ \\ ${ }^{a}$ Mental Health Center Glostrup, Copenhagen University Hospital, Broendby, Denmark; \\ ${ }^{b}$ Center for Subjectivity Research, University of Copenhagen, Copenhagen, Denmark
}

\section{Keywords}

Fantasy · Schizophrenia spectrum disorders · Imagination · Schizophrenia - Schizotypal disorder · Mental imagery . Phenomenology Psychopathology

\begin{abstract}
The Examination of Anomalous Fantasy and Imagination (EAFI) is an instrument for a semistructured, phenomenological exploration of psychopathology of imagination. The EAFI provides a conceptual-descriptive framework to address such experiences. It consists of 16 main items, sometimes divided into subtypes. We suggest that the anomalies of imagination explored by the EAFI reflect an alteration in the structure of consciousness and belong to a fundamental, generative layer of psychopathology with relevance to differential diagnostic purposes.

(c) 2018 S. Karger AG, Basel
\end{abstract}

\section{Introduction}

The Examination of Anomalous Fantasy and Imagination (EAFI) is an instrument for a semistructured, phenomenological exploration of experiential anomalies of imagination. The EAFI requires familiarity with the phe- nomenology of general imagination, which is described in a twin paper by Rasmussen et al. [1]. The history and the development of the EAFI as well as reliability data are also described in this introductory twin paper. Briefly, the development of the EAFI was originally stimulated by data from self-disorder research [2]. The items of the EAFI were formed on the basis of recent conceptual and phenomenological studies of disorders of imagination [3, 4] informed by phenomenology and philosophy of mind as well as classical psychopathological literature.

\section{The Order of the Checklist}

The EAFI consists of 16 items, some further divided into subtypes, and each contains a definition of the phenomenon being assessed (with considerations about the delimitation of the item from other complaints) and prototypical examples of the patients' self-descriptions. The items identify certain anomalous aspects of the experiential structure that patients may verbalize with different vocabulary. Questions are suggested to each item, but if an interviewer decides to use some of them, they should be modified according to the content, the context, and the flow of the interview. We point this out, since the interview targets experiences that are impossible to explore in

\section{KARGER}

(c) 2018 S. Karger AG, Basel

E-Mail karger@karger.com

www.karger.com/psp
Andreas Rosén Rasmussen, MD

Mental Health Center Glostrup

Broendbyoestervej 160

DK-2605 Broendby (Denmark)

E-Mail Arr@dadlnet.dk 
a structured interview, as addressed in details elsewhere $[5,6]$. Accordingly, a valid exploration presupposes that the interviewer has become familiar with the definition of the items and the use of the instrument. We have included an overview of the items and subtypes in Appendix A as a support during the interview.

It is extremely important that the items are not mutually independent symptoms. They are interdependent and overlapping aspects of an underlying disturbance of the structure of imaginative experience, with a gestalt-like character. Accordingly, a longer description of a particular experience will often satisfy the definition of several items, and these should then all be rated. This is illustrated by the examples in the EAFI.

In our own research, the 16 main items have been scored on a lifetime basis. Scoring the subtypes will inevitably inflate the score. Therefore, it is always necessary to indicate whether only the main items or the subtypes have been included in the total score. Certain items partly overlap items in the Examination of Anomalous SelfExperience (EASE) [7], the Bonn Scale for the Assessment of Basic Symptoms [8], or the Examination of Anomalous World Experience (EAWE) [9]. We have summarized these overlaps in Appendix B.

\section{Guidelines for the Interview}

The assessment of the phenomena listed in the EAFI is similar to the recommendations for phenomenological, semistructured interviews addressing self-disorders [7] or psychopathology in general [10]. We recommend that the interview begins with a social- and illness history, which will frequently provide a natural entry into certain EAFI items. The EAFI may be integrated into other interview instruments targeting either general or specific domains of psychopathology.

A basic concern is the pre-reflective quality of the experiences addressed in the interview. They are usually not in the focus of thematic attention. The interviewer must therefore encourage the patient to acquire an introspective attitude and keep the interview conversational thus allowing the patient to reflect about disturbances of tacit and intrinsic aspects of consciousness. Mental symptoms are not predefined, well-demarcated notions that already lie defined in the patient's consciousness ready to be elicited by specific questions, i.e., as third-person data [11]. Rather, they will emerge with a gestalt-like character in the interaction between the patient's narrative and the interviewer's elaborating and clarifying questions. The in- terviewer must suspend natural assumptions in order to faithfully explore the articulation of any object of inquiry. It is especially important to go behind the patient's use of standard statements such as "fantasy," "imagination," or "inner scenarios." It often happens that the patient's use of the terms such as "obsession" or "flashback" is different from how these terms are understood in psychopathology. Frequently, patients express themselves through metaphors, which, rather than being "just metaphors," may be a pregnant and concrete way of verbalizing such anomalous experiences.

Ideally, the interview takes place as a mutual interactive reflection between the interviewer and the patient [7]. The interviewer poses an (usually) open-ended question to which the patient attempts a response leading to further questions by the clinician, perhaps by proposing an example, which is then clarified by the patient's own words and examples. Items should never be rated on the basis of a simple "yes" but always be based on the patient's own descriptions and examples. An initial "no" to an area of enquiry may also frequently be replaced by rich descriptions later in the conversation when the same issues are addressed with other questions or in a different thematic content.

Obviously, the interview is difficult to conduct with severely psychotic patients suffering from globally disordered attention and cognition. In these cases, it is advisable to postpone the interview and await clinical improvement.

\section{Spatiotemporal Constancy}

The patient describes a stable quasi-spatial structure of the image that endures as a temporally persisting object. I.e., imagery is experienced with fixed locations and relations of the elements or a sense of depth (it can be described what are above, below, to the left, distant, or close etc.). The imagery may endure for minutes, but may also be very brief or even flashy, yet still with a clear spatial articulation. In general, the patients also describe a richness of details in the imagery, but that is not necessary to rate this item.

Often, the patients describe that they are able to $e x$ plore the imagery in a way that appears similar to the exploration of a perceived object. E.g., the patient can focus at the lower left part of the fantasy image, shift his attention to another part, and return to the previous one while the imagery retains stability during the experience (subtype 2). Explorability often overlaps with a sense of experiential distance (item 3.2). 
Such perceptualization of imagery [3] may be associated with fantasy, memories, anticipations, or during reading. It is relevant to explore whether obsessions, ruminations, or suicidal or paranoid ideation possess such perceptualized structure.

\section{Subtype 1: Spatiotemporal Stability Subtype 2: Explorability of Imagery}

\section{Examples}

- "I have had the same sequence in the head repeatedly: In great details, I see someone stepping out on the road in front of my bike, and I run them down. The movie runs constantly, the location of things is very distinct. It is like watching a movie or really seeing an event. I can see the woman I run into and all the people in the background, all the cars on the other side of the road" (rate items 1.1, 2, and 8.4).

- She is afraid of bacteria and watches entire movies in her head about how the food has been exposed to disgusting things. For example, that some raw meat has contaminated her soup bowl in the dishwasher. She can be completely lost for minutes and examine everything that she has touched the last hour in details. These are very clear images that are stable for minutes and somehow zoom in on details. However, she does not evoke that herself. It just happens (rate items 1.1 and 1.2 , as well as 2).

\section{Suggested Questions}

Do you have very vivid imaginations or inner pictures? Can you describe what you imagine then?

Can your imagery be very detailed? Can you describe an example of such details?

Do you imagine clearly what is located upward, downward, to the left, and to the right?

Is there a sense of depth? Is something closer than other things? Are the imagery 3D-like? Can you describe that?

Can you explore details and change focus while the rest of the fantasy remains stable? Like studying a painting? Can you describe further?

\section{Autonomy}

The imagery acquires its own flow, sequence, or development, "like a movie", independently of the will of the subject. The subject may also describe a sense of passive reception of such images that "run by themselves".
Autonomy of imagery does not exclude explorability (item 1.2) because the patient may explore the independently flowing images. Furthermore, autonomy should not be confused with involuntariness (item 9). The subject may initiate an image, which then articulates itself in an autonomous way, or the subject may succeed in suppressing the image through an intense effort to direct his attention elsewhere.

\section{Examples}

- "The images run by themselves. I do not control them but kind of observe what happens" (rate items 2 and 3.2).

- She imagined herself sitting in the cinema at a planned trip later that day: "Yes, it is very vivid, almost like a movie. It repeats itself. It begins again if I turn my attention away. The things are detailed if I focus, but I can change focus and the other things so to say stay there. Then I can return and examine it later.... The movie is just behind my eyes. It is very much like being there oneself, it is just there inside (points to her head)" (rate items 1.2, 2, 3.1, and 3.2 on the basis of this description).

- Sometimes he tries to induce the fantasies by thinking intensely on a subject and "suddenly an image pops up and, so to say, continues by itself."

\section{Suggested Questions}

Does your imagination proceed and develop by itself? As if it has its own flow independent from your will?

\section{Localization and Sense of Experiential Distance}

\section{Overlaps EASE 1.8}

The imagery is experienced as being specifically localized in the head or the images possess mutual spatial relations or are in movement (subtype 1).

Subtype 2 describes a profound sense of experiential distance between the experience of imagery and the sense of self. The patient describes that he observes or inspects his imagery "from afar" as an inner object. Sometimes, the patient observes his imaginary object in order to know what he imagines.

Normally, imaginations are experienced in the firstperson perspective as permeated by the sense of subjectivity; my imagination coincides with my sense of self. In other words, consciousness has no spatial structure, and images are not observed like a perspectival object. Rather, 
one immediately knows the content of an imagination without any distance between the subject and imagery.

\section{Subtype 1: Localization of Imagery Subtype 2: Sense of Experiential Distance between Imagery and Self}

\section{Examples}

- He always "sees" the images at the front of his head above the eyes (he shows the location with his hands) (subtype 3.1).

- "Actually I often see several movies running at the same time: There might also be images of myself crashing on my bike or being knocked down by a truck. They run simultaneously like multiple rail tracks, and I keep an eye on all of them" (subtype 3.2; also rate item 2).

- She has many images in the head and she observes them in order to know what she is thinking. The last couple of weeks, there have frequently been too many unconnected images and movies. She cannot repress those images and she becomes confused (subtype 3.2; also rate items 9.1 and 12 ).

\section{Suggested Questions}

Do you experience that the images have a location in your head or mind?

Do you ever experience a kind of distance between yourself and the imagery? As if you were looking at a picture?

Has it ever been necessary to observe your imagery in order to know what you are thinking?

\section{Intense Affects}

Intense anxiety, anger, wonder, joy, or other intense affects during imaginations - Anxiety or uneasiness related to memories of specific, disturbing events in personal life, as well as phobic anxiety should not be rated.

Normally, affects in imagination are poor, mimed, and superficial since we intend an irreal and absent object [12]. My discomfort when imagining a traffic accident does not correspond to my fear when actually witnessing such an event. In the case of phobic disorders, the difference between the anxiety of anticipation of the phobic stimulus in thoughts or imagery and the anxiety during the actual exposure is clearly preserved [4].

\section{Examples}

- "The emotions are within me, not in the fantasy. So what I could feel in the fantasy, I really feel. The emotions can be just as strong in imagination as in reality. I imagined an argument with my friend - that she was very angry and all sort of things would happen. I could feel that quite powerfully and became very sad and depressed even though it had never happened."

\section{Suggested Questions}

Do you become very emotional during the fantasy? Have you felt very anxious (angry/sad/euphoric [depending on the context])?

\section{Imagination as Multimodal Perceptualization}

The perceptualized imagery is accompanied by activation of other sensory modalities such as an acoustic or tactile quality of imaginary contents, e.g., the person describes that she also "hears" sounds or feels sensations ("as-if being touched") in the fantasy.

\section{Example}

- He heard another patient telling about how she broke her nails. Meanwhile, he had those unpleasant images of what she told, and he felt it almost himself in his own finger.

\section{Suggested Questions}

Is it like almost hearing sounds during the fantasies? Or like being touched?

\section{Anomalous Vivid Imaginary Experience, Unspecified}

\section{Subtype 1: Brief Intense Imagery}

Intense, intrusive "flashes" or very brief episodes of anomalous and disturbing "vivid imagery" - Should not be rated if the patient is rated for any of items 1-3.

\section{Subtype 2: Anomalous Imaginative Experience,}

\section{Other Type}

This item targets descriptions of anomalous imagery or fantasies that the interviewer finds aberrant but is unable to rate elsewhere in this checklist. 


\section{Example}

- If her boyfriend uses the word "knife," she feels uncomfortable. The word triggers some short flashes where she sees herself being cut. Paper can trigger the same (one could cut one's finger on the edge of the paper).

\section{Violent, Macabre, or Bizarre Content}

Imaginations with an elaborated content of explicitly violent, macabre, or bizarre sexual character - This may be associated with vivid imagery but can also be described as more vague images, thoughts, or ruminations etc.

\section{Subtype 1: Experienced as Intrusive, Unpleasant, and Unwanted}

Subtype 2: Willingly Instigated or Entertained

\section{Ruminations-Obsessions}

\section{Equivalent to EASE 1.6}

(Usually) disturbing persistence or recurrence of certain intrusive contents of consciousness (e.g., thoughts, images, or impulses) - Ruminations may be associated with any past event or have the form of meticulous recapitulation of remembered events or conversations of the day. Obsessive phenomena can have various contents like aggression, contamination, sexual themes, religion (sacrilege), symmetry, or counting etc.

There are 5 subtypes, which may coexist. Phenomena described here (in particular 8.4) may also overlap with items $1-7$. In both cases, rate all relevant items.

\section{Subtype 1: Primary Ruminations}

Here, the patient is unable to find any reason for his tendency to obsessive-like mental states; he simply rethinks and relives what happened during the day or in the past - apparently not motivated by perplexity, paranoid attitude, or sense of vulnerability or inferiority (as in subtype 2).

\section{Subtype 2: Secondary Ruminations}

The obsessive-like states appear as a consequence of a loss of natural evidence, disturbed basic sense of self, or hyperreflectivity [13], or they appear to be caused by more primary paranoid phenomena (e.g., suspiciousness or self-reference) or a depressive state.

\section{Subtype 3: True Obsessions}

Ego-dystonic (as in obsessive-compulsive disorder): the patient considers them as silly, strange, both because of their content and their involuntary intrusion with ongoing internal resistance, and a content that is not horrid or macabre.

\section{Subtype 4: Pseudo-Obsessions}

Obsession-like phenomena, which appear more as ego-syntonic (hence there is none or only occasional resistance), frequently with pictorial imaginative character and with a content that is directly aggressive, sexually perverse, or otherwise bizarre - May be anxiety provoking and associated with intense affects.

\section{Subtype 5: Ruminations/Obsessions with Rituals/ Compulsions}

Any of the four phenomena described above plus rituals or compulsive behaviors.

\section{Disturbance of Control}

\section{Subtype 1: Lack of Control - Experience Persists Involuntarily}

Being unable (or being only occasionally able) to divert one's attention or otherwise repress unwished imaginary or obsessive-like experiences by an effort of the will - The subject experiences a disturbance of her ability to exercise control over her thematic awareness, i.e., what content she chooses to make an object of attention. Includes cases in which the experience unwillingly persists in consciousness although the patient, to some extent, can simultaneously direct his attention elsewhere.

\section{Subtype 2: Lack of Activity of the Will}

Patients describe that they never or rarely make efforts to suppress such experiences; the possibility simply does not come to their mind. This item should not be rated if the patient willingly entertains fantasies, e.g., due to fascination or enjoyment (as in item 7.2).

\section{Examples}

- Sometimes she can pull herself together and suppress those movies, but it is impossible if it is about raw meat or bacteria (subtype 1).

- He is absorbed in fantasies and it does not occur to him that he could interrupt them (subtype 2). 
Suggested Questions

Have you ever been unable to repress, perhaps just for a short while, these imaginations or divert your attention? Do the images continue even though you focus on something else?

\section{Loss of Ipseity}

Encompassed by EASE 1.2, Loss of Thought Ipseity

A feeling that certain imagery may appear as deprived of the tag of mineness. Imagery feels anonymous or otherwise indescribably strange (but not primarily in the sense of content), perhaps without a connection to the patient's self, perhaps as if it was not generated by the patient. Yet, the patient does have the rational conviction that these images are generated in him and that he is their origin.

It is important to realize that the basic phenomenon in question, which is disturbed, is ipseity, i.e., automatic mineness or first-person perspective $[7,13]$. In the case of thoughts or ideas suddenly popping up in the mind ("Einfall"), or obsessions, the sense of immediate or prereflective ipseity never questions itself.

\section{Examples}

- "I do not feel the images of my family getting hurt are myself. I know it is my own head, but it feels as if a photo becomes interjected into my head."

\section{Suggested Questions}

Have you ever experienced that the images (or "fantasy," "scenario," or "inner movies" etc.) in some way felt alien, or in another way different? Almost as if they were not your own imaginations? Can it be as if the fantasies are not imagined by you but more in you?

\section{Image Interference}

Encompassed by EASE 1.1, Thought Interference Imaginations semantically disconnected from the main line of thinking appear involuntarily (not necessarily quickly or many), break into the main line of thinking, and interfere with it. Such imagery is often (but not always) emotionally neutral and does not need to have a special or extraordinary meaning.

\section{Example}

- He can have pleasant fantasies of a beautiful, blissful landscape, but then there might suddenly come an image where the same landscape appears burned and horrid. Like when a slide is inserted on top of the previous slide.

\section{Suggested Questions}

Have you ever experienced that some new, strange, or surprising fantasies or images unexpectedly appear with a completely new content and disturb your thoughts? That some imaginations appear that do not fit into your chain of thoughts?

\section{Image Pressure}

Encompassed by EASE 1.3, Thought Pressure

A sense of many images with different, unrelated, or remotely related meaning/content that pop up and disappear in quick sequences without the patient being able to suppress or guide this appearance/disappearance of (ever new) contents of consciousness. Alternatively, all these images seem to the patient to occur at the same time (simultaneously). This symptom involves a lack of control, many changing images, but also a lack of a common theme, and hence a loss of coherence or meaning for the patient. The semantic content of the imagery may be distressing but also neutral or even trivial, without any special personal significance.

\section{Suggested Questions}

Have you ever experienced having many images at the same time or shifting quickly? Unrelated to each other? Images, you cannot control?

\section{Existential Reorientation in Fantasy}

Fantasy life expresses a fundamental change of metaphysical worldview and/or hierarchy of values and interests. Of course, metaphysical questions are a frequent theme in human thought, but here these themes enact a basic, experiential disturbance of the relation between self and world [13].

Frequent themes are fantasies providing access to hidden layers of reality, the nature of consciousness and the mind, the meaning of existence, supernatural phenomena, mysticism and religion (especially Eastern), eternity and transcendence, conflicts of good and evil, uni- 
versal peace, fate of humanity, profound ancient rituals or traditions, or alternative understanding of science, nature, psychology, or health etc.

Frequently, such fantasies seem related to self-disturbances such as a diminished sense of basic self, lack of common sense, or solipsistic experiences $[7,13]$. To be rated, such fantasies must be frequent and not isolated episodes of pondering "basic questions." Do not rate in case of hypomanic or manic state.

\section{Examples}

- Since he was a teenager, he has had daydreams, often for many hours daily. It could be about winning the lottery, but also more grandiose like being superman or otherwise having supernatural powers. He could imagine being the ruler of the world and sometimes felt like he was the center of the world. Or it could be more dramatic or odd as when he imagined blowing up the whole earth from a spaceship (rate items 13 and 14).

- She reads and watches a lot of manga (Japanese cartoons) and enjoys imagining alternative developments of the plot for a couple of hours every evening. She believes that when you die, you enter the world of fantasy. You can then choose which universe to inhabit in the afterlife. Asked about her own preferences, she tells that she has not decided yet. She considers many manga universes and new appear every year (note the solipsistic theme; rate item 13, 14, and 16.2).

- He does not know whether these memories really happened? The images are very clear, but not himself in the images. He can be in doubt about what is the new me and what is the old me? He does not know the proper definition of himself and tries to rethink all his memories in order to become clarified about it (rate items 8.2, 13, and 15.1. His ruminative occupation with possible memories appears secondary to a disturbed sense of basic self [EASE 2.1]).

\section{Suggested Questions}

Have you ever had daydreams or fantasies about existential matters? About religious, philosophical, or supernatural themes? Or about your identity, who you really are?

\section{Preoccupation with Fantasy Life}

The patient spends an excessive amount of time and energy imagining or daydreaming (suggested cutoff: more than $1 \mathrm{~h}$ daily) and/or certain fantasies have an idiosyncratic value and existential importance.

The content might include peculiar, overvalued interests or concerns (perhaps rated under item 13) but also more common existential themes from the personal identity of the patient such as relations, career ambitions, social status, or central fears, hopes and values. Such fantasy life may not in itself be anomalous. However, the patient seems to engage these questions just as much or perhaps more in his fantasy life than in the shared social world (often accompanied by varying degrees of retreat from social interactions).

\section{Examples}

- She avoids being present in the now and rather entertains daydreams about getting married, having children, or buying a nice car. She can also elaborate on something she read and invent whole stories. About being slim or meeting some famous people.... She can have such fantasies many times during the day but in particular the last hour before she goes to sleep. Actually, she gets stressed if this hour is interrupted.

- He has recurrent vivid imagery of himself lying in decay in a coffin, unable to get out. Although he feels terrified, he is also curious, and usually he does not try to divert his attention. He continually speculates whether after death, he will have an actual experience of being trapped in a coffin and experience the decay of his body. He has tried to reassure himself with various religious points of view, but he cannot escape the thought that it might be "as I actually see it in imagination" (rate items 4, 7.1, 8.4, and 14).

\section{Suggested Questions}

Do you have pleasant fantasies? Do you have particular fantasies or daydreams that you evoke on purpose?

Do these fantasies have a lot of importance to you? Can you spend quite some time daydreaming? 


\section{Disturbances of Irreality}

Irreality indicates that the image is "just an image" and therefore does not evoke an emotional, cognitive, or behavioral response in the same manner as a perceptual object does $[3,12,14]$. In the act of imagining, we are immediately (self)-aware that we are imagining and do not have to reflect upon the act in order to identify it as imagination [13].

\section{Subtype 1: Erosion of Irreality}

Related to EASE 1.10, Inability to Discriminate

Modalities of Intentionality

The patient has brief occasions or longer periods with difficulties in the immediate awareness of the experiential modality of the imaginary experience (i.e., that it is a fantasy). This includes when the patient is uncertain whether his experience is a fantasy, a memory, or a perception. Such, normally implicit, awareness of the modality of the intentional act can be temporally delayed or it may require a (short) effort of reflection to determine.

\section{Examples}

- I know that the imagery is not real, but I can get in doubt. I have to close my eyes a couple of seconds or squeeze my arm to be sure.

- I know it is my own imagination... I mean, when I am in it, it is sometimes very intense. But as soon as it is over, I know at least that it was an imagination. At other times, I have these scenarios during ordinary conversation; then I know all along that it is imagination.

\section{Suggested Questions}

Can you be uncertain whether your imaginations are just imaginations? Do you somehow have to be attentive or make an effort to clarify that?

Can you be uncertain whether something in your mind is a memory or an imagination?

\section{Subtype 2: Relating to Imagery as to a Perceptual Object (Correcting, Being Surprised)}

The subject has certain attitudes and reactions to imagery that normally are only relevant toward perceived, socially shared objects. It includes concerns about whether certain details of the imagery are "correct," "realistic," or "as I want it to be," or an experience of a clear sense of surprise during an imaginative experience.

\section{Examples}

- If I know something in the fantasy is not correct, not as I remember that room, then I try to correct it. I divert my attention, focus on something different, and then I almost force an image in, and when I focus on it again, it is as it should be.

- Sometimes, when I get lost in my thoughts, something happens in the fantasy and I get a shock and come to myself. I know the images go on in my head, but anyway I might get frightened.

\section{Suggested Questions}

Are you concerned about whether you imagine things in the correct way? Do you sometimes attempt to correct some images? Do you feel a sense of surprise about something that you imagine?

\section{Subtype 3: Micropsychotic Episode}

The normally implicit awareness that the imaginary experience is irreal and private (discriminated from the shared, social world) is absent for a short duration (seconds to minutes) - Often, the patient lacks awareness of her surroundings.

\section{Examples}

- He has daily, recurrent, involuntarily popping up, "very vivid, inner visions" in which he kicks the head of an unknown man lying defenseless on the ground until the head is severed from the body. He feels angry during the experience but shameful after. He becomes "carried away" with no urge to resist and forgets the world around him. During his "vision" and seconds thereafter, it seems "as if these events are really happening." Immediately after, however, he realizes that it was this well-known, absurd fantasy (rate items 4, 7.1, 8.4, 9.2, 15.3, and 16.1).

- During a period with suicidal thoughts, she had an episode of some images while she stood at a train platform. She imagined herself from the outside jumping out in front of an incoming train. When a train actually arrived, she came to herself and was for a few seconds convinced that she had actually jumped.

\section{Suggested Questions}

Have you actually thought that a fantasy or some images were reality while you experienced them? 


\section{Subtype 4: Imagination Influencing Choices or Behavior}

Choices are made and/or actions taken on the basis of imaginations and fantasies. If behavior can be classified as compulsions (being repetitive and based on obsessional content), this item should not be rated.

\section{Examples}

- A patient describes spatialization of imagery of a planned visit to the cinema (see item 2 ). She adds that she did not go to the cinema anyway because in this anticipatory imagery, she appeared distracted and not paying attention to the movie. So there was no point in going.

- She often has exactly the same fantasy of her father being hurt in a traffic accident. Mostly, she knows that it is fantasy - she has learned by her therapist to ignore it, since she cannot suppress it. But sometimes the movie "overwrites" her own thoughts, and she is unsure whether it really happens during the experience. Once, it was so powerful that she had to phone her father to assure herself that he was alive (rate items 8.4, 9.1, 15.1, and 15.4).

\section{Suggested Questions}

Have you made decisions or taken some action due to these or other imaginations?

\section{Lack of Insight}

The patient does not consider the anomalous imaginative experiences to be absurd, excessive, or irrelevant. Or she does not identify the content as anomalous (i.e., as uncommon or indicating illness).

Insight refers to an immediate judgment or evaluation that identifies an (usually obsessional) experience as nonsensical (ego-dystonic), and accordingly the patient attempts to ignore or suppress such thoughts and images (resistance). The item is rated if the patient lacks insight into one of the phenomena covered by the EAFI even if she shows full insight into other experiences.

\section{Subtype 1: Lack of Insight during the Experience}

In the case of apparent insight, it should be explored whether the patient had such insight immediately, i.e., during the obsessive or imaginary experience (intact insight, the item is not rated), or insight has only been acquired after the experience is over when the patient can take a reflective stance toward her past experience in a more calm state.

\section{Subtype 2: Enduring Lack of Reflective Insight}

Lack of insight at the time of the interview or for a longer period after the experience.

\section{Examples}

- When she imagined those scenes about being attacked by this stranger, she really felt she was in danger. But a few minutes later, such ideas seemed far out (item 16.1).

- He spends a lot of the evening recapitulating everything that happened during the day. It has always seemed a good thing not to forget anything important. But lately, he has started thinking that other people apparently do not make an issue out of it (items 8.1 and 16.2).

\section{Suggested Questions}

Could those things (obsessional content) really happen? What did you think about that during the experience? Do you think that those imaginations are reasonable? What do you think about those daydreams being so important to you? 


\section{Appendix A}

Examination of Anomalous Fantasy and Imagination (EAFI) Item Key List

\begin{tabular}{|c|c|c|c|}
\hline 1 & Spatiotemporal constancy & 8.4 & Subtype 4: Pseudo-obsessions \\
\hline 1.1 & Subtype 1: Spatiotemporal stability & 8.5 & Subtype 5: Ruminations/obsessions with rituals/ \\
\hline 1.2 & Subtype 2: Explorability of imagery & & compulsions \\
\hline 2 & Autonomy & 9 & Disturbance of control \\
\hline 3 & Localization and sense of experiential distance & 9.1 & Subtype 1: Lack of control - experience persists \\
\hline 3.1 & Subtype 1: Localization of imagery & & involuntarily \\
\hline 3.2 & $\begin{array}{l}\text { Subtype 2: Sense of experiential distance between } \\
\text { imagery and self }\end{array}$ & $\begin{array}{c}9.2 \\
10\end{array}$ & $\begin{array}{l}\text { Subtype 2: Lack of activity of the will } \\
\text { Loss of ipseity }\end{array}$ \\
\hline 4 & Intense affects & 11 & Image interference \\
\hline 5 & Imagination as multimodal perceptualization & 12 & Image pressure \\
\hline 6 & Anomalous vivid imaginary experience, unspecified & 13 & Existential reorientation in fantasy \\
\hline 6.1 & Subtype 1: Brief intense imagery & 14 & Preoccupation with fantasy life \\
\hline 6.2 & $\begin{array}{l}\text { Subtype 2: Anomalous imaginative experience, other } \\
\text { type }\end{array}$ & $\begin{array}{l}15 \\
15.1\end{array}$ & $\begin{array}{l}\text { Disturbances of irreality } \\
\text { Subtype 1: Erosion of irreality }\end{array}$ \\
\hline $\begin{array}{l}7 \\
7.1\end{array}$ & $\begin{array}{l}\text { Violent, macabre, or bizarre content } \\
\text { Subtype 1: Experienced as intrusive, unpleasant, and }\end{array}$ & 15.2 & $\begin{array}{l}\text { Subtype 2: Relating to imagery as to a perceptual object } \\
\text { (correcting, being surprised) }\end{array}$ \\
\hline & unwanted & 15.3 & Subtype 3: Micropsychotic episode \\
\hline 7.2 & Subtype 2: Willingly instigated or entertained & 15.4 & Subtype 4: Imagination influencing choices or behavior \\
\hline 8 & Ruminations-obsessions & 16 & Lack of insight \\
\hline 8.1 & Subtype 1: Primary ruminations & 16.1 & Subtype 1: Lack of insight during the experience \\
\hline 8.2 & Subtype 2: Secondary ruminations & 16.2 & Subtype 2: Enduring lack of reflective insight \\
\hline 8.3 & Subtype 3: True obsessions & & \\
\hline
\end{tabular}

\section{Appendix B}

Examination of Anomalous Fantasy and Imagination (EAFI) Compared to Examination of Anomalous Self-Experience (EASE), Bonn Scale for the Assessment of Basic Symptoms (BSABS), and Examination of Anomalous World Experience (EAWE)

\begin{tabular}{lllll}
\hline EAFI & & EASE & BSABS & EAWE \\
\hline 3.1 & Localization of imagery & 1.8 & & \\
8 & Ruminations-obsessions & 1.6 & C.1.2 (partly) & \\
& & & B.3.2 (partly) & \\
10 & Loss of ipseity & 1.2 & & \\
& & 2.2 .1 & C.1.1 & \\
11 & Image interference & 1.1 & C.1.3 & C.7.1 \\
12 & Image pressure & 1.3 & A.6.2 (partly) & (partly) \\
\hline
\end{tabular}

As a rule, the EAFI targets a subgroup of experiences that is included in broader items in the other instruments. However, definitions may not be exactly identical. 


\section{References}

1 Rasmussen AR, Stephensen H, Nordgaard J, Parnas J: A phenomenological approach to psychopathology of imagination: development of a descriptive instrument - examination of anomalous fantasy and imagination. Psychopathology 2018, DOI: 10.1159/000488463.

-2 Parnas J, Henriksen MG: Disordered self in the schizophrenia spectrum: a clinical and research perspective. Harv Rev Psychiatry 2014; 22:251-265

-3 Rasmussen AR, Parnas J: Pathologies of imagination in schizophrenia spectrum disorders. Acta Psychiatr Scand 2015;131:157-161.

4 Rasmussen AR, Parnas J: Anomalies of imagination and disordered self in schizophrenia spectrum disorders. Psychopathology 2015; 48:317-323.
5 Nordgaard J, Revsbech R, Sæbye D, Parnas J: Assessing the diagnostic validity of a structured psychiatric interview in a first-admission hospital sample. World Psychiatry 2012; 11:181-185.

6 Nordgaard J, Sass LA, Parnas J: The psychiatric interview: validity, structure, and subjectivity. Eur Arch Psychiatry Clin Neurosci 2013;263:353-364.

7 Parnas J, Møller P, Kircher T, et al: EASE: Examination of Anomalous Self-Experience. Psychopathology 2005;38:236-258.

8 Gross G, Huber G, Klosterkötter J, Linz M: Bonner Skala für die Beurteilung von Basissymptomen. Berlin, Springer, 1987.

9 Sass L, Pienkos E, Skodlar B, Stanghellini G, Fuchs T, Parnas J, Jones N: EAWE: Examination of Anomalous World Experience. Psychopathology 2017;50:10-54.
10 Jansson L, Nordgaard J: The Psychiatric Interview for Differential Diagnosis. Cham, Springer International Publishing, 2016.

11 Parnas J, Sass LA, Zahavi D: Rediscovering psychopathology: the epistemology and phenomenology of the psychiatric object. Schizophr Bull 2013;39:270-277.

12 Sartre J.-P: The Imaginary: A Phenomenological Psychology of the Imagination. Routledge Classics. London, Routledge, 2010.

13 Parnas J, Sass L: The structure of self-consciousness in schizophrenia; in Gallagher S (ed): The Oxford Handbook of the Self. Oxford, Oxford University Press, 2011, pp 521546.

14 Husserl E: Phantasy, Image Consciousness, and Memory, 1898-1925. Collected works/ Edmund Husserl. Dordrecht, Springer, 2005. 